Cadernos de Literatura em Tradução, n. 5, p. 139-147

\title{
Três poetas: Racine, Shakespeare e Nerval
}

\author{
Renata Cordeiro
}

Jean Racine (1639-1699) Le songe d’Athalie

... Un songe (me devrais-je inquiéter d'un songe?)

Entretient dans mon coeur un chagrin qui le ronge.

Je l'évite partout, partout il me poursuit.

C'était pendant l'horreur d'une profonde nuit.

Ma mère Jézabel devant moi s'est montrée,

Comme au jour de sa mort pompeusement parée.

Ses malheurs n'avaient point abattu sa fierté;

Même elle avait encor cet éclat emprunté

Dont elle eut le soin de peindre et $d^{\prime}$ orner son visage,

Pour réparer des ans l'irréparable outrage.

"Tremble, m'a-t-elle dit, fille digne de moi.

Le cruel Dieu des Juifs l'emporte aussi sur toi.

Je te plains de tomber dans ses mains redoutables,

Ma fille." En achevant ces morts épouvantables,

Son ombre vers mon lit a paru se baisser;

Et moi, je lui tendais les mains pour l'embrasser.

Mais je n'ai plus trouvé qu'un horrible mélange

D'os et de chair meurtris, et traînés dans la fange,

Des lambeaux pleins de sang, et des membres affreux, Que des chiens dévorants se disputaient entre eux. 
CORDEIRO, Renata. Três poetas: Racine, Shakespeare e Nerval.

\section{O sONHO DE ATÁLIA?}

... Só um sonho (será que me devo inquietar?)

Nutre em meu peito o mal que o sói remastigar.

Sempre o evito, porém me segue pelo mundo.

Deu-se no horror da noite e do escuro profundo.

Jezebel, minha mãe, assim me apareceu:

Com pompa ornada, igual ao dia em que morreu.

Tinha a mesma altivez, malgrado a sua dor;

Tinha até mesmo aquele emprestado fulgor

Com o qual enfeitava e pintava o semblante,

Para lhe reparar os anos ultrajantes.

"Treme, filha, tu que és digníssima da mãe.

Pois o Deus dos judeus te vencerá também,

Cruel. Ai! Vais cair em suas mãos temíveis,

Minha filha." Depois das palavras terríveis,

Rumo ao meu leito, a sombra iniciou a descida;

Para a abraçar, fiquei com as mãos estendidas.

Mas só achei na lama o horrendo emaranhado

Dos ossos e da carne então mortificados,

Trapos cheios de sangue e membros que assustavam, Pelos quais já os cães, devorantes, brigavam. (Atália, II Ato, Cena V)

1 Atália foi rainha de Judá, ficha de Acab e de Jezebel. Desposou Jorão, filho de Josafá, e por morte do filho, o rei Ochozias, subiu ao trono depois de haver mandado matar os netos. Escapou à carnificina Joas, salvo pelo grão-sacerdote Joad, que mais tarde o fez subir ao trono. Atália foi assassinada pelo povo (século IX a.C.). Na tragédia de Racine, que Voltaire qualificou de "a obraprima do engenho humano", o tema é a conspiração de Joad, a entronização de Joas e a morte da rainha. 


\section{WiLLIAM SHAKESPEARE}

IV

Unthrifty loveliness, why dost thou spend Upon thyself thy beauty's legacy?

Nature's bequest gives nothing but doth lend, And, being frank, she lends to those are free.

Then, beauteous niggard, why dost thou abuse The bounteous largess given thee to give?

Profitless usurer, why dost thou use

So great a sum of sums yet canst not live?

For, having traffic with thyself alone,

Thou of thyself thy sweet self dost deceive.

Then how, when nature calls thee to be gone,

What acceptable audit canst thou leave?

Thy unused beauty must be tombed with thee, Which, used, lives the executor to be.

IV

Ó perdulário amor, desperdiças, então, Só contigo o legado imenso da beleza? A natureza arrenda e não faz doação, Generosa, ela empresta aos que agem com franque-

za.

Por quê, formoso avaro, estás sempre a abusar Da oferenda que cabe a ti oferecer? Usurário sem lucro, então por que poupar Supremo ouro se não lhe irás sobreviver? Se só contigo mesmo agora negocias Estás negando a ti teu doce complemento. E quando a natureza, enfim, chamar-te, um dia, Terá o teu balanço um bom recebimento? Na tumba morrerá a desusada beldade, Usa-a, que te fará a derradeira vontade. 
CORDEIRO, Renata. Três poetas: Racine, Shakespeare e Nerval.

\section{GÉrard de Nerval (1808-1855) \\ EL DESDICHADO (VERSÃO CONSAGRADA)}

Je suis le ténébreux, - le veuf, - l'inconsolé, Le prince d'Aquitaine à la tour abolie:

Ma seule étoile est morte, - et mon luth constellé Porte le soleil noir de la Melancolie.

Dans la nuit du tombeau, toi qui m'as consolé, Rends-moi le Pausilippe er la mer d'Italie, La fleur qui plaisait tant à mon coeur désolé, Et la treille où le pampre à la rose s'allie.

Suis-je Amour ou Phébus?... Lusignan ou Biron?

Mon front est encore rouge du baiser de la reine; J'ai rêvé dans la grotte où nage la sirène...

Et j'ai deux fois vainqueur traversé l'Achéron: Modulant tour à tour sur la lyre d'Orphée Les soupirs de la sainte et les cris de la fée. 


\section{El DESDICHADO' (VERSÃO CONSAGRADA)}

Eu sou o tenebroso, ${ }^{2}$ - o viúvo, ${ }^{3}$ - o inditado, príncipe gaulês que um dia abaixo veio: ${ }^{4}$ Morreu-me a estrela, - e o meu laúde constelado ${ }^{5}$ Tem da Melancolia o sol negro no meio. ${ }^{6}$

Tu que sempre me tens no luto consolado, Dá-me esse mar da ltália e o Pausílipo outeiro, A flor ${ }^{8}$ que me agradava o peito desolado E a videira em que a parra e a rosa têm o veio. ${ }^{9}$

Sou Biron, Lusignan? ...Brilhante Febo, Amor? 10

Do beijo da Rainha a face está corada; ${ }^{11}$

Sonhei naquela gruta em que a sereia nada. ${ }^{12}$

E do Aqueronte eu fui o duplo vencedor: ${ }^{13}$

Na lira que é de Orfeu, alternando a balada

Dos suspiros da santa ${ }^{14}$ e dos gritos da fada. ${ }^{15}$ 
CORDEIRO, Renata. Três poetas: Racine, Shakespeare e Nerval.

\section{El DESDICHADO (VARIANTE DA VERSÃO CONSAGRADA)}

Je suis le Ténebreux, le Veuf, I'Inconsolé:

Le prince d'Aquitaine à la Tour abolie.

Ma seule Étoile est morte: et mon luth constellé

Porte le Soleil Noir de la Melancholie.

Dans la nuit du Tombeau, Toi qui m'a consolé

Rends-moi le Pausilippe er la mer d'Italie, La Fleur qui plaisait tant à mon coeur désolé Et la Treille où le Pampre à la Vigne s'allie!

Suis-je Amour ou Phoebus, - Lusignan ou Biron? Mon front est rouge encor du baiser de la Reine, J'ai dormi dans la Grotte où verdit la Sirène.

Et j'ai deux fois, vivant, traversé l'Achéron: Modulant et chantant sur la lyre d'Orphée Les soupirs de la Sainte, - et les cris de la Fée. 


\section{EL DESDICHADO (VARIANTE DA VERSÃO CONSAGRADA)}

Eu sou o Tenebroso, o Viúvo, o Inditado:

Príncipe cuja Torre aquitana existia.

Morreu-me a Estrela: e o meu laúde constelado

Traz o Sol Negro em si, o da Melancolia.

Dá-me, Tu que me tens da Tumba consolado, O Pausílipo, e o mar que na Itália irradia, A Flor que me agradava o peito desolado E a Parreira em que a Vinha ao Pâmpano se alia!

Quem, Biron, Lusignan, Amor, Febo, serei?

Do beijo da Rainha a face purpureja, Dormi na Gruta onde a Sereia verdeja.

E duas vezes, vivo, o Aqueronte cruzei:

Com a lira de Orfeu, e cantando a balada

Dos suspiros da Santa, - e dos gritos da Fada.

\section{NOTAS}

'Personagem de Walter Scott, em Ivanhóe: cavaleiro andante, cuja divisa era a palavra espanhola "Desdichado" (desditado/ desditoso, inditado ou inditoso.

2 "Belo Tenebroso" era a alcunha de Amadis de Gaula, herói de um célebre romance de cavalaria, atribuído a Vasco de Lobeira (século XIV). Príncipe infeliz no amor, é o protótipo do cavaleiro andante, fiel à sua dama e aos preceitos da cavalaria. 
CORDEIRO, Renata. Três poetas: Racine, Shakespeare e Nerval.

3 "Viúvo" substituiria "Príncipe Morto", no original.

${ }^{4}$ Nerval se julgava descendente do proprietário de um castelo na Aquitânia.

${ }^{5}$ A "única estrela" de Nerval é azul e rosa, as duas metades de um único amor. $\bigcirc$ "laúde" ou "alaúde" é um instrumento musical de cordas de origem oriental - provavelmente árabe -, para o qual foi escrita a primeira música clássica.

${ }^{6}$ Gravura de Alberto Dürer (1514). Também em Viagem ao Oriente, Nerval alude a essa gravura: "o sol negro da melancolia, que derrama raios escuros no rosto sonhador do anjo de Alberto Dürer, por vezes também se levanta nas planícies luminosas do Nilo."

${ }^{7}$ Outeiro perto de Nápoles, onde estaria o túmulo de Virgílio, em que Petrarca teria plantado um loureiro.

${ }^{8}$ Segundo o próprio Nerval, trata-se da ancólia, flor ambígüa, símbolo da tristeza e da alagria, que dá nas cores azul ou rosa (as cores da "única estrela").

9 Ainda segundo Nerval, tal videira existiria nos jardins do Vaticano.

10 Nerval acreditava na metempsicose (reencarnação das almas). O senhor de Biron (Dordogne) era amigo de Henrique IV. Lusignan era o nome de uma ilustre família feudal, cujo castelo foi fundado em Poitou, segundo a lenda, pela fada Melusina (ver nota 15), e que dominou por muito tempo o Marche e a Angoulème. Quanto a Febo, pode haver uma dupla referência: ora a Febo, o Brilhante, epíteto do deus Apolo, ora a Gastão III, chamado de Febo pela sua bela cabeleira loira, conde de Foix (1331-1391). Apesar de violento (matou o seu único filho), foi um político inteligente. Aliou-se a Carlos $V$ e mostrou-se esclarecido protetor das letras e das artes, escrevendo um célebre Tratado de caça. Amor ou Cupido é um deus fabuloso, filho de Vênus, dotado de asas, arco, alforje com flechas e, muitas vezes, de uma venda nos olhos.

11 Poder-se-ia tratar tanto da Rainha de Sabá, rainha da Arábia também conhecida por Balkis, cujo beijo afastaria a infeli- 
cidade, quanto de Margarida de Escócia - delfina da França e primeira esposa de Luís XI - que beijou o poeta Alain Chartier (século XV), apesar da sua fealdade. Disse: "Não beijei o homem, mas sim a preciosa boca de onde saíram tão belas frases e tão virtuosas palavras".

12 Alusão a uma gruta na baía de Nápoles.

${ }^{13}$ Rio dos Infernos, duas vezes atravessado por Orfeu, quando ele estava em busca de Eurídice.

14 Virgem Maria.

${ }^{15}$ Melusina, fada que os romances de cavalaria e as lendas do Poitou representam como antepassada e protetora da casa de Lusignan. Melusina arrancou de Raimundino de Lusignan a promessa de que ele nunca a veria aos sábados e lhe construiu o castelo do seu nome. Mas Raimundino, infiel à sua promessa, descobriu o segredo de Melusina que todos os sábados se transformava, parcialmente, em serpente. Ela desapareceu e, desde então, vem ao fosso do castelo soltar gritos de dor, sempre que um Lusignan está ameaçado de morte 